\title{
'Abraca-F***-You!': Gaming, podcasting and collaboration in The Adventure Zone
}

\begin{abstract}
The Dungeons \& Dragons-inspired podcast, The Adventure Zone (TAZ) (2014present), which is run by the McElroy family, is an ongoing narrative about three adventurers who work to find and destroy seven powerful Grand Relics. The narrative incorporates several different genres, themes, and both player and non-player characters. During the podcast, the youngest brother, Griffin, explains settings and story elements so that his two brothers, Justin and Travis, and his father, Clint, can react to them while playing characters that they have created. This paper argues that TAZ models a storytelling approach that incorporates and streamlines radio drama storytelling, chance, and roleplay into an organic, collaborative narrative. I examine TAZ's audio gameplay, the discussions amongst the players between scenes (metagaming), and the metatextual discussions in the Lunar Interludes and other metaepisodes, in order to track the progression of the story and explore how the storytelling methods contribute to an engaging narrative.

Keywords: Dungeons and Dragons, podcast, storytelling strategies, radio drama, gamification
\end{abstract}

\section{Introduction}

The Adventure Zone (TAZ) is a podcast performed by the McElroy family: brothers Griffin, Justin and Travis, and their father Clint (McElroy 2014-2017). Together, they play Dungeons \& Dragons $(D \& D)$, recording remotely from their homes in various cities in the USA. Griffin acts as the Dungeon Master (DM) and is responsible for guiding the narrative and playing non-player characters (NPCs). Justin, Travis and Clint are player characters (PCs); Justin plays a high elf magician named Taako, Travis plays a human fighter named Magnus Burnsides, and Clint plays a dwarf cleric named Merle Highchurch. Each of the players, including the DM, exercise control over their characters' actions by rolling dice and keeping track of their abilities via their characters' Character Sheets. The first season of $T A Z$ is episodic, with 69 episodes split into micro story arcs of about ten episodes each. These micro-arcs are separated by character-focused episodes called Lunar Interludes, in which the players purchase magical items and level up. The first season, or macro-arc, discussed in this paper is called the Balance Arc and ran from 3 December 2014 until 17 August 2017. The podcasts were uploaded bi-weekly and averaged at around an hour and a half per episode.

This paper argues that $T A Z$ models a storytelling approach that develops the $D \& D$ gameplay style into an organic, collaborative narrative. $D \& D$ is a tabletop game that is usually played as a series of prompts and chance dice- 
rolls that serve as the basis for an ongoing story. There are no 'winners' in the game. Instead, players and the DM come together to enjoy story-based roleplaying. The rules and playing style of $D \& D$ and tabletop games are important to the thesis of this article, but explaining the rules in detail is beyond this article's scope. I will give detail as necessary when the gameplay elements contribute directly to the development of the narrative. For a clear and detailed explanation of all elements mentioned in this article, see the Player's Handbook (Wizards of the Coast 2014a) and the Dungeon Master's Guide (Wizards of the Coast 2014b).

$D \& D$ is improvisational and collaborative in nature, but ordinarily games are not played as performances with an audience in mind. Because $T A Z$ is a podcast narrative, the gameplay must be accessible and engaging. The McElroys' innovative playing style, which incorporates and streamlines radio drama techniques, chance, and roleplay, makes the narrative more immersive for the audio-based format and contributes to an engaging story. For the purposes of this paper, I will examine TAZ's gameplay (and the changes that the McElroys made to traditional $D \& D$ rules), the discussions amongst the players between scenes (which is known as 'metagaming'), and the players' out-ofcharacter discussions in the metaepisodes (episodes that are less about gameplay and more about character management and out-of-character explorations of the story). I have chosen to include all of these elements in my analysis because they are all experienced by the listeners as part of the narrative whole, assuming that the listener is engaging with the podcast in a linear fashion. Therefore, these elements contribute to the listener's understanding of the characters and their world. As I will explain later in this paper, the spoken word becomes text in the podcast format. As the narrative develops, the metatextual discussions affect the narrative as much as the scenes that are performed in-character.

This paper is split into two sections: the first explores how the McElroys incorporate and streamline various elements of radio drama, chance, and roleplay, in order to make their $D \& D$ game appropriate for a podcast format. The second section goes into more detail about how various game rules play out and affect the narrative. The intention here is to breakdown what elements appear to work in the $T A Z$ narrative so that other creators may explore this collaborative storytelling style.

\section{Streamlining the game for an audience}

As discussed above, the $D \& D$ playing style is traditionally played in a tabletop setting where players and their DM construct a story together while occupying the same physical space. They will often gather around a gameboard or map, with miniature figurines that represent their characters placed strategically around the board. Depending on the players' interests, there may be more emphasis on character development than on maintaining the narrative arc, or vice versa. In order to make the game more accessible to outside audiences, some changes need to be made. In particular, the transition to the podcast format cuts the physical elements from the $D \& D$ game. By incorporating radio drama elements, the players can avoid unnecessarily confusing listeners who cannot see a gameboard or characters.

Andrew J Bottomley writes that podcasts have their roots in theatre and other oral traditions, notably radio drama. He writes: '[t]he podcast is a scripted, dramatized serial narrative that is written, performed, and produced to be heard. This fundamental structure and approach are hallmarks of radio drama' 
(Bottomley 2015: 183). Although podcasting initially presented itself as a potential rival to traditional radio, it has not usurped radio's position as the mainstream preference for listening - it has become more of a space for niche content (Berry 2015; Murray 2009). That being said, McClung and Johnson write that podcast listeners are also interested in the freedom of choice that podcasting represents (McClung \& Johnson 2010). A listener may stream or download a podcast at their leisure, listen to previous episodes, and play-back certain segments on their device of choice. This makes the podcast format a different listening experience than traditional radio.

While this difference in listening experience may seem like a minor detail, it is a detail that allows fictional works like $T A Z$ to be embraced so readily. With fan culture often working from a transformative, deeply immersive space (Jenkins 2006; Stedman 2012; Curwood, Magnifico \& Lammers 2013; Scott 2015), the fact that fans can listen to the show over and over, discuss theories, and go back to listen to episodes to find relevant plot points, allows them to be more engaged than they would be with a live radio drama (a one-time performance). This also requires some stronger narrative development because the creators are required to maintain a stricter narrative continuity, which will be explored later in this paper. Essentially, if a podcast does not use a script (as is the case in $D \& D$ podcasts where much of the narrative is up to the dice rolls), the podcast's improvisational nature is open to continued and retroactive scrutiny by the fans, and so the players need to be aware of this when they are performing. In audio narratives, narration becomes text.

The audience for most podcasts and radio dramas are known as 'narratees' the narration is meant for them so that they can interpret what is happening in the narrative. In $T A Z$, the audience are absentee narratees - they are present while the events are unfolding but the majority of Griffin's narration is meant for his family (the players) as they are the PCs whose behaviour and choices dictate where the story goes, and they are the ones who must act on his narration to collaborate and build the narrative. Matt DelConte notes the 'absentee narratee' (2007: 431) is assumed to be present for the proceedings even though the narrator cannot know that the narratee is present. Despite being assumed to be present, the absentee narratee does not have any effect on the events that they are present for. As the listening audience is not the primary recipient of the podcast's narration, the players need to be aware of their storytelling approach so that it does not alienate the listeners. This involves generally guiding the listeners through the characters' emotions, paying particular attention to describing physical space (given, as stated above, the traditional $D \& D$ game includes a physical board, which cannot be the case in an audio narrative) and maintaining character voices to differentiate between dialogue and narration.

With regards to the relationship between physical space and narration, audio narratives are considered 'highly stimulating mediums for the imagination' (Rodero 2012: 46) because they require the listener to imagine what the story looks like based only on audio input. Emma Rodero notes that audio-narratives that rely heavily on the narrator to essentially explain to the audience what they see and hear can be highly engaging because the narrator acts as a guide, organising the events of the story into a manageable (usually linear) narrative, and enabling the listener to follow what is happening (Rodero 2010). This storytelling strategy can, however, be supplemented and enhanced with dramatisation - that is, using actors to perform a script (Rodero 2012). A dramatised story 'contributes to a far greater extent [than straight narration] when it comes to encouraging the imagination of the listener thanks to a greater rate of vividness and a heightened generation of images' (Rodero 2012: 54). Radio dramas often include a mixture of narration and dramatisation by acting 
out scripted scenes and using stage directions to guide the listeners' mind through images. This is also a typical narration style of $D \& D$, and one of the reasons that the game lends itself so well to the radio drama/podcast format. Griffin, in his capacity as DM, will introduce scenes that the players are interacting with by describing the physical space that would usually be represented by the board:

GRIFFIN: There are a few militia wagons surrounding the entrance to the building. There - the building is now almost completely enveloped in these vines. And the vines have also started to sort of spread, almost like carpeting the street around the Goldcliff Trust, and so these militia people are - are giving it a pretty wide berth. There's about a dozen or so militia folks surrounding the entrance to this building, and in the back of the crowd, near a particularly large wagon is a, uh, broad, mustachioed man, in his late 60s, you would think, who is yelling gruff orders at his, uh, at his underlings. (McElroy 2015b)

The players, reacting to this information, then narrate the actions that their characters take:

TRAVIS: I run up and start blithely attacking them. Just hacking and slashin'. Giving it a couple chops of the ol' axe...

CLINT: I have channel divinity, charm animals and plants... If I present my holy symbol - which, I think you all know I have my Extreme Teen Bible - then invoke the name of my deity, which I'm sure you remember is Pan - So, I can actually ask it to part, right? (McElroy 2015b)

$T A Z$ incorporates a mixture of straight narration (from Griffin) and dramatisation (from the in-character PCs and NPCs). Griffin acts as narrator by explaining what the characters see and hear, and some of their behaviour in each scene, but instead of using a script he improvises much of what he describes based on the rolls of the dice.

GRIFFIN: (in response to Travis's 23 perception check roll) Twenty-three, okay, you see the shit out of everything. Travis, you see about 200 feet up, lying in the road, two figures that (with your incredible perception check), you can actually tell with your eagle eyes - that they are two dead horses lying in the middle of the road. (McElroy 2014a)

This is where the $D \& D$ gameplay interacts with radio drama to create the McElroy's dynamic narrative style.

The McElroys also use film conventions to describe action and how the viewer should visualise particular scenes, which adds an additional element of imagery to the text while simultaneously taking advantage to the expectation that the viewer will have visual literacy - something that the early progenitors of radio drama did not have. For example, in Episode 69, Griffin describes the opening scene as follows: 'We see a close-up of Davenport's face, his teeth gritted, his knuckles tight across the spokes of the Starblaster's wheel'. Similarly, they refer to scenes moving in quick succession as 'montages' during descriptions in order to give the listener a sense of time passing.

TRAVIS: Now, Griffin, would you say it is a simultaneous montage of her teaching me thieves' arts and us carving a 
duck?

GRIFFIN: Uh, yes. It's side by side.

TRAVIS: Concurrent montage! (McElroy 2016b)

By incorporating these film conventions that tap into the listeners' visual literacy, the McElroys are able to create a third layer of engagement by transforming expectations of the format. Use of film conventions is beyond the scope of this paper - which is primarily interested in the audio elements of the narrative - but this interaction between audio and visual in description would be an interesting line of enquiry for further study.

Both the PCs and NPCs use character voices so that there is an auditory distinction between narration and drama. This helps the listener to imagine what is happening in-game, while simultaneously being aware of the creative decisions being made behind the scenes. With regards to immersion, character voices are an important element in oral narrative to distinguish between narration and performance. An ongoing joke in the $T A Z$ series is Clint's inability to maintain his character's 'voice'. While this is a point of humour for the players, character voices are extremely useful from the perspective of the listener - as discussed above, the distinction between in-game play and metagaming helps the listener to discern what is performance and what is discussion. As the story progresses, all the players become better at maintaining character voices and Griffin develops different voices for each of the NPCs. This particular roleplay approach allows him to introduce characters by voice alone - if the players recognise the voice, they often introduce the character without Griffin's prompting.

GRIFFIN: You hear a voice say: (in a higher, sweet voice) Hello, sirs! (Justin, Clint, and Travis all gasp.)

TRAVIS (as MAGNUS): It's ... it's the Boy Detective! It's Angus! (McElroy 2015c)

Because the medium is entirely audio, there needs to be a separation between action and speech because speech enacts action and crafts the scene that is being presented. Character voices also become a humorous tool when the players forget to use them. During the Murder on the Rockport Limited miniarc, Griffin, after listening to the players make fun of anMcElroy NPC's voice, informs them that their rude commentary was in-character the whole time and that the NPC is offended (McElroy 2015a). In the same way, during the Live Boston Stunt Spectacular, Travis shouts at Clint: 'Elvish is not dorky, Dad!' to which Griffin replies: 'That was totally in - that had to be in-fiction, you saying "Elvish is not dorky, Dad" to Merle' (McElroy 2016a). In radio drama, the actors would be trained to distinguish dialogue and narration with vocal cues, but unless it is a strong part of the characters' roleplay, it rarely comes up in $D \& D$ gameplay. In this case, by incorporating this element into their game, the McElroy brothers are able to make the audio experience more accessible to their audience.

The $T A Z$ narrative is collaborative in nature, but it is an unusual collaboration. Griffin, the DM, has plans and intentions for the macro-arc - that is, the overall narrative arc of The Adventure Zone, which culminates in a three-part finale (titled Story and Song). Just as in traditional $D \& D$, the DM's control of the narrative is limited to the desires of his players and the roll of the dice. There is some relative freedom for the players, Justin, Travis, and Clint, to have more control over their characters' choices, but they do not know what each of the 
micro-arcs are going to entail until they are being narrated by Griffin. This is demonstrated when, during the Eleventh Hour arc, they applaud Griffin as soon as they realise what he has been planning: that this particular arc is a Groundhog Day-style repetition of the same hour in which the players have to save a town from a giant purple worm (McElroy 2016c). Because three of the four collaborators do not know what is coming, their behaviour during the arcs may go directly against what their DM is planning. One decision can completely rewrite the story. As DM, Griffin needs to manage his own expectations and the expectations of the players in a way that is narratively cohesive and engaging for the listeners. For example, during a conversation between Merle and The Hunger, during the Stolen Century arc, Merle improvises a question that significantly changes the tone of the scene:

CLINT (as MERLE): Yeah, there is something I'd like to know. Are you my friend?

GRIFFIN: Hmm.

TRAVIS: Not what I was expecting.

GRIFFIN: But very fucking good. Give me a minute, I'm reeling a little bit. (McElroy 2017c)

Griffin's storytelling capabilities are quite strong, but it is arguably the players' ability - and the freedom they exercise in the hybrid $D \& D$ space that Griffin has established - that makes the narrative stronger and more engaging because there is always an element of unpredictability that Griffin must account for. With three players improvising while one maintains control over the narrative as a whole, there remains a sense that the story is driving towards a conclusion even as the roleplaying scenes create depth for characters and interactions. It is also a more organic collaboration because the interactions are improvised in the spur of the moment.

\section{Changes in Gameplay}

$D \& D$ is a very complex table-top game that incorporates several gaming styles - notably role-play and chance. Every player has a character which comes with a set of numbered statistics (strength, dexterity, health, etc.) and personality traits, and during the game the players roleplay these characters. The more incharacter the players are, the more immersive the overall game becomes. The players roll dice and improvise/dictate what their character does as a result of each dice roll; most actions and decisions are accompanied with a roll.

In $T A Z$, the three players and DM initially adhere closely to the traditional $D \& D$ game rules. Over the course of the podcast, however, they begin to transform game elements to suit the podcast structure. While the McElroys roll dice to guide their actions, in accordance with the rules of the game, they do so mainly for important actions and checks (such as perception checks, armour class checks, damage checks, etc.). They also incorporate rules from earlier editions of the game in order to put more emphasis on certain rolls. The result is a hybrid-version of the $D \& D$ game that is more narrative-heavy and character-focused than usually expected in traditional games. Griffin notes in a metatextual episode that he made the decision to cut certain game rules and alter certain scenes for expedience, to ensure that the podcast is interesting to listen to as well as interesting to perform (McElroy 2017a). 
In $D \& D$, characters behave according to an alignment. The alignment is designed to give players specific personality types to roleplay, with each alignment demonstrating how a character should perform. The alignments, paraphrased for expedience, are gridded out as follows:

Lawful Good

Follows the law even if

the law goes against their moral code

Lawful Neutral

Follows an ethical code of their own design

Lawful Evil

Exploits the system of laws for their own gain
Neutral Good

Will only break the law if they believe that it is morally right

\author{
Chaotic Neutral \\ Motivated by self-interest \\ and unpredictability
}

Will pursue what they think is right at any cost

\author{
Cares very little about \\ good and evil
}

\section{Neutral Evil}

Motivated by selfinterest, but will not do harm unless it is expedient or rewarding
Chaotic Evil

Chaos for the sake of chaos

Characters in $D \& D$ are also divided into race, sub-race, class and background. As briefly discussed above, Taako, Merle and Magnus are a high elf magician, dwarf cleric, and human fighter respectively, and these races and classes come with different proficiencies and features that guide how a character can be played. According to the Player's Handbook (Wizards of the Coast 2014a), dwarves are creatures of tradition and will honour those traditions to a fault. Similarly, high elves love art and poetry, and tend to be curious, focused, and relentless. If the characters perform according to the specifics of these divisions, then it should theoretically be quite easy to predict how they will behave in a given situation, and therefore easy as a DM to guide the narrative towards a specific, desired goal.

The McElroy family initially perform their characters with reference to the alignments, races, and classes. But within the first episode, their tongue-incheek playing style morphs the characterisation so that it becomes less and less aligned with the traditional $D \& D$ performance. Merle, as the dwarf cleric, has an irreverent approach to religious practice ('I've never been a church guy' [McElroy 2016b]), while Taako the high elf magician is performed as aloof with a very short attention span, instead of being very serious about his magic as would be expected (Abraca-Fuck-You! [McElroy 2014b]). Magnus initially had a very dark backstory (according to metadiscussion in the first episode), which Travis abandons because it does not fit the tone of the show (2014). By transforming these characters beyond the perceived limitations of the $D \& D$ character style, the players create a more immersive experience because they are able to perform their characters organically, even if it means potentially limiting the predictability of their characters for their fellow collaborators and the DM. This is an example of the cast of $T A Z$ getting creative and flexible with the rules of $D \& D$ as they were originally intended in order to make the game more engaging as a narrative intended for absentee narratees.

During the Eleventh Hour arc, Griffin sets up a scenario where the PCs have the opportunity to return to their own backstories to change something that has negatively affected their characters. Once again, it is Travis, playing Magnus, 
who throws the metaphorical wrench into Griffin's plans. As Griffin states, 'I fully fucking thought that Magnus was going to take the [chalice, a Grand Relic that allows its user to travel in time] and I had two episodes worth of stuff [planned]' (McElroy 2017a). In this case, the collaborators did not necessarily have conflicting plans for the story; it was more the case that one collaborator's understanding of a character conflicted with another's plans, and so they had to work together to find the necessary common ground so that the narrative would still work cohesively and be true to character motivations. It is an excellent example of improvised collaboration in practice.

One of the strongest elements of the $T A Z$ narrative is its characterisation. The four creators collaborate on the narrative itself, but the characters who carry that narrative are created by the players and are constantly open to new dimensions being drawn out in their roleplay. In fact, during an episode in the Eleventh Hour arc, Griffin expresses some surprise at Merle's backstory, which Clint had previously not disclosed: 'Oh, interesting! Alright' (McElroy 2016e). Similarly, when Clint explains his choice to make Merle mistrustful of NPCs who might take his place in the trio, Griffin expresses similar shock: 'Wow, I never - fuck, man!' (McElroy 2017a). In this case, the collaboration is such that even the DM does not know everything about the characters and the choices they may make, which helps to develop the narrative beyond what the DM had planned and create a richer narrative universe.

Metagaming is a game-style in which players speak out-of-character to explain and justify their actions, behaviours and personality traits, which is what Clint and Griffin are doing in the example above. Metagaming is usually discouraged in $D \& D$ according to the Dungeon Master's Guide (Wizards of the Coast $2014 b$ ). Given that $T A Z$ is being performed for an absentee narrate audience beyond the three players and the DM, their performance incorporates metagaming through metaepisodes, which unpack the creative decisions that the collaborators make and how they have transformed the game to make it more appropriate for the audio narrative. By titling these episodes as separate from the main narrative (Lunar Interludes and The The Adventure Zone Zone), viewers have the option to skip them if they prefer to avoid metagaming. There is also some metagaming in the episodes, where players will note that they themselves are aware of a narrative convention or device which their characters will not know about, and this may affect their playing decisions. For example, Travis explains during the Suffering Game arc that, if he were listening to this episode as part of the audience, he would be advising the characters to do certain things that he cannot justify through his roleplay in-game:

TRAVIS: I'm having this moment that I have any time that I watch any kind of, like, movie or TV show and, like, things have happened that some characters know about that other characters don't where I'm just, like, screaming at them. Like, "Just tell - just be open in communication and everybody tell everybody exactly what happened!" And I'm sitting here, like, as Travis wanting to tell the Director everything that we know. But at the same time just not knowing if I can trust her. I just wanted to share that moment with the audience and with you guys. That I have no idea what to do. (McElroy 2016d)

In the case of the $T A Z$ podcast, this metagaming can be useful because it helps to justify narrative decisions for the absentee narratees and allows the other collaborators to work with and incorporate those decisions into their own gameplay. When playing traditional $D \& D$, the main audience for the story is usually the players themselves, but in this particular instance the players and the DM are working within a listener-driven medium and so the rules and 
playing style must be altered slightly to accommodate that. These relatively minor decisions to alter traditional gameplay contribute to a more engaging narrative experience for the audience.

$D \& D$ game rules can have significant consequences on the narrative. For example, during the Lunar Interludes the PCs can shop for gear at Fantasy Costco, which is stocked with items suggested by fans of the show. Here, Griffin is generally careful to ensure that nothing is too powerful that the characters could overwhelm his storytelling capacity. But during Lunar Interlude II (McElroy 2015c), Griffin adds an item called the 'Flaming Poisoning Raging Sword of Doom' which was submitted by the eight-year-old son of a listener. This sword is impossibly powerful, but Griffin set the price at 60,000 gold pieces to keep the PCs from being able to buy it. However, he also introduced two other magical items during Lunar Interlude IV (McElroy 2016d): the Slicer of Tapeer-Wheer Isles, which allows a PC to persuade an NPC to trade their most valuable item with a high persuasion check, and a guidebook which allows characters to gain advantage on specific checks. Taako buys both of these items, and then the following scene takes place:

JUSTIN (as TAAKO): Garfield.

GRIFFIN (as GARFIELD THE DEALS WARLOCK): Yes?

JUSTIN (as TAAKO): I have something that I think is really going to interest you.

GRIFFIN: (realising what his brother is planning) Oh my god!

JUSTIN (as TAAKO): This is the Slicer of Tapeer-Wheer Isles, and I notice that you have a really cool sword - it's a Flaming Poisoning Raging Sword of Doom? I believe it's called?

GRIFFIN: Oh my god.

JUSTIN (as TAAKO): And I'm looking at your entire stock and it does seem to me that that's your most valuable possession, would you say that's accurate? (McElroy 2016d)

In this case, the gameplay leads in a direction that the DM had not intended. Justin wins the roll and Griffin honours Taako's ability to out-deal Garfield the Deals Warlock, owner of Fantasy Costco, and buy the impossibly powerful sword. Occasionally, Justin as Taako will hold Griffin accountable to both the improvised nature of the story and the gamification element in order to exercise this power as a collaborator:

GRIFFIN (as BARRY BLUEJEANS): (trying to tell Taako something personal and potentially embarrassing)It's, don't worry about - it's nothing. I-uh, I-

JUSTIN (as TAAKO): Barry.

GRIFFIN (as BARRY BLUEJEANS): We should get back to the ship -

JUSTIN (as TAAKO): Barry, I rolled an eleven [Heart check]. You gotta tell me, Barry. (McElroy 2017b)

When dice rolls work in the player's favour, it can often mean that the DM has to scrap their original plans and come up with something new. In the Suffering 
Game arc, which is styled as a gameshow where the contestants have to prove their desire for the Grand Relic by making sacrifices and winning challenges, Griffin sets up a scenario that would see Magnus murdered and his soul sent to the astral plane. As Griffin explains in the metatextual episode, The The Adventure Zone Zone, 'I had a whole thing in the astral plane [planned for Magnus]'. During the episode, however, when Magnus's soul was removed from his body, Taako and Merle intervene using the spells Magic Jar and Planer Ally, allowing them to save Magnus's soul and put it into a mannequin. Griffin, as the DM, could have arranged for Taako and Merle to fail in saving Magnus by enforcing certain rules that would have made the rescue impossible. This would have allowed him to continue the narrative as he had planned it. Instead, he allows the narrative to progress in the direction that his players choose. This is a typical example of the collaborators at work: playing out the narrative based on strong character decisions and in-game battle tactics that each collaborator must respond to organically. Griffin has said that he enjoys the players taking control of scenes in this way. With regards to the previous example, he says: 'You guys did a cooler thing there than I had envisioned' (McElroy 2017a).

Occasionally, Griffin will give the characters opposing options by reaching out to them through conflicting NPCs, and this creates an opportunity for the narrative to go in multiple directions depending on the PCs' choices. At the conclusion of the Eleventh Hour arc, Griffin performs a young girl NPC handing Magnus a mysterious scroll, while another NPC encourages him not to open it:

GRIFFIN: Magnus, in your head, you hear the voice of the red robe that you've seen a few times now and he says: (as the Red Robe)Magnus. If you open that tube, Magnus, it's going to be harder for me to protect you.

TRAVIS (as MAGNUS): Yeah, bite my ass. (As commentary) I open the tube. (McElroy 2016f)

In this particular example, Griffin, as the DM, has a certain desire and plan for the narrative but manages to offer his collaborators a choice in how they are going to perform. The expected $D \& D$ game-play style, in which players are given space to perform according to their PCs' characterisation, is useful in a situation where there are many collaborators but it also makes it very difficult to control the narrative. This creates a more organic (if terrifying) storytelling experience for the collaborators.

The most significant change to the $D \& D$ gameplay came in the narrative's penultimate micro-arc: the Stolen Century. In order to develop the narrative and gameplay style to ensure more flexibility for PCs, Griffin introduces a radical change in game-play during the Stolen Century arc that, he explains, will help move away from some of the clunkier, less immersive aspects of $D \& D$ game style. Griffin uses the Stolen Century arc to workshop a new style of game; the players are introduced to a scene and asked what they would like to do, and then they roll two D6 dice to determine their success. This gives the players a scenario and a level of success that they are free to interpret, allowing the players to react to the 'flavour' of a scene. The earlier example, in which Taako rolls an eleven for his heart check in a discussion with Barry Bluejeans, is an example of this gameplay in action: a roll of 1-6 is a failure, a 7-9 is a mixed success, and a 10-12 is a complete success. This change in gameplay remains true to the nature of the game-based podcast while allowing the collaborators more creative freedom. It is an interesting playing style choice which does increase the performers' ability to 'play' in the scenes, but I would argue that 
the strength of this decision lies in the fact that the players had several previous arcs to develop their characterisation and playing style so that they are comfortable as collaborators; the scenes would perhaps not have worked as well if they were unfamiliar with each other, the world, or the narrative threads that other characters develop until that point.

\section{Conclusion}

The Adventure Zone transforms and develops traditional $D \& D$ gameplay to more readily suit the podcast form by encouraging collaborator flexibility, and merging gamification with radio drama-style mechanics. Strong characterisation and the alteration of key $D \& D$ rules allow the collaborators to cooperate to form a cohesive, organic narrative, with the DM and players interacting with each other in order to develop the story as a whole. Griffin, as the DM, may make specific choices with the macro-arc in mind, but his fellow collaborators can exercise equal control over character choices and major plot points. If Griffin, as the keeper of the macro-arc, wants a character to do something specific, he needs to justify it in-game. In this sense, the narrative is organically collaborative. Although there was some narrative discontinuity in the first arc that needed to be justified later on, this could have been addressed by the collaborators knowing at the outset that this game would be long-form instead of a brief one arc performance, which is what it was originally intended to be. The flexibility of DM and the innovative character creation of the three players contributes to an engaging narrative as the first season drew to a close.

\section{Works cited}

Berry, R 2015 'A Golden Age of Podcasting? Evaluating Serial in the Context of Podcast Histories', Journal of Radio \& Audio Media 22, 2: 170-178 return to text

Bottomley, AJ 2015 'Podcasting, Welcome to Night Vale, and the Revival of Radio Drama', Journal of Radio \& Audio Media 22, 2: 179-189 return to text

Curwood, JS, AM Magnifico \& JC Lammers 2013 'Writing in the Wild: Writers' Motivation in Fan-Based Affinity Spaces', Journal of Adolescent \& Adult Literacy 56, 8: 677-685 return to text

DelConte, M 2007 'A Further Study of Present Tense Narration: The Absentee Narratee and Four-Wall Present Tense in Coetzee's Waiting for the Barbarians and Disgrace', Journal of Narrative Theory 37, 3: 427-446 return to text

Jenkins, H 2006 Fans, Bloggers and Gamers: Exploring Participatory Culture, New York University Press, New York return to text

McClung, S \& K Johnson 2010 'Examining the motives of podcast users', Journal of Radio and Audio Media 17: 82-95 return to text

McElroy, G 2014-2017 The Adventure Zone: http://www.maximumfun.org/shows/adventurezone (accessed 18 October 2018) return to text

McElroy, G 2014a 'Ep. 1. Here There Be Gerblins - Chapter One', The Adventure Zone: http://www.maximumfun.org/adventure-zone/ep-1-here-there-be-gerblins-chapter-one (accessed 1 October 2018) return to text

McElroy, G 2014b 'Ep. 4. Here There Be Gerblins - Chapter Four', The Adventure Zone: http://www.maximumfun.org/adventure-zone/ep-4-here-there-be-gerblins-chapter-four (accessed 1 October 2018) return to text 
McElroy, G 2015a 'Ep. 12. Murder on the Rockport Limited - Chapter Three', The Adventure Zone: http://www.maximumfun.org/adventure-zone/ep-12-murder-rockport-limited-chapterthree (accessed 1 October 2018) return to text

McElroy, G 2015b 'Ep. 18. Petals to the Metal - Chapter One', The Adventure Zone: http://www.maximumfun.org/adventure-zone/ep-18-petals-metal-chapter-one (accessed 1 October 2018) return to text

McElroy, G 2015c 'Ep. 28. Lunar Interlude II: Internal Affairs', The Adventure Zone: http://www.maximumfun.org/adventure-zone/ep-28-lunar-interlude-ii-internal-affairs (accessed 1 October 2018) return to text

McElroy, G 2016a 'The Adventure Zone: The Live Boston Stunt Spectacular', The Adventure Zone: http://www.maximumfun.org/adventure-zone/adventure-zone-live-boston-stuntspectacular (accessed 1 October 2018) return to text

McElroy, G 2016b 'Ep. 40. Lunar Interlude III: Rest \& Relaxation', The Adventure Zone: http://maximumfun.org/adventure-zone/ep-40-lunar-interlude-iii-rest-relaxation (accessed 1 October 2018) return to text

McElroy, G 2016c 'Ep. 41. The Eleventh Hour - Chapter One', The Adventure Zone: http://www.maximumfun.org/adventure-zone/ep-41-eleventh-hour-chapter-one (accessed 1 October 2018) return to text

McElroy, G 2016d 'Ep. 50. Lunar Interlude IV: The Calm Before The Storm', The Adventure Zone: http://www.maximumfun.org/adventure-zone/ep-50-lunar-interlude-iv-calm-storm (accessed 1 October 2018) return to text

McElroy, G 2016e 'Ep. 51. The Suffering Game - Chapter One', The Adventure Zone: http://www.maximumfun.org/adventure-zone/ep-51-suffering-game-chapter-one (accessed 1 October 2018) return to text

McElroy, G 2017a 'The The Adventure Zone Zone - Maxfundrive 2017', The Adventure Zone: http://www.maximumfun.org/adventure-zone/adventure-zone-zone-maxfundrive-2017 (accessed 1 October 2018) return to text

McElroy, G 2017b 'Ep 62 The Stolen Century - Chapter Three', The Adventure Zone: http://www.maximumfun.org/adventure-zone/ep-62-stolen-century-chapter-three (accessed 1 October 2018) return to text

McElroy, G 2017c 'The Adventure Zone Ep. 63. The Stolen Century - Chapter Four', The Adventure Zone: http://www.maximumfun.org/adventure-zone/adventure-zone-ep-63-stolencentury-chapter-four (accessed 1 October 2018) return to text

Murray, S 2009 'Servicing "self-scheduling consumers"': Public broadcasters and audio podcasting', Global Media and Communication 15: 197-219 return to text

Rodero, E 2010 'Imagery in a radio story', Paper presented at the Colloque: Creation Radiophonique. Radio et Narration: Le réenchantement? Brussels, Belgium, 19-20 November return to text

Rodero, E 2012 'Stimulating the Imagination in a Radio Story: The Role of Presentation Structure and the Degree of Involvement of the Listener', Journal of Radio \& Audio Media 19, 1: $45-60$ return to text

Scott, S 2015 'The Hawkeye Initiative: Pinning Down Transformative Feminisms in ComicBook Culture through Superhero Crossplay Fan Art', Cinema Journal 55, 1: 150-160 return to text

Stedman, KD 2012 'Remix Literacy and Fan Compositions', Computers and Composition 29: 107-123 return to text

Wizards of the Coast 2014a Player's Handbook, Wizards of the Coast, Washington return to text

Wizards of the Coast 2014b Dungeon Master's Guide, Wizards of the Coast, Washington return to text 
Jessica Seymour is an Australian researcher and lecturer at HU University of Applied Sciences, Utrecht. Her research interests include children's and YA literature, transmedia storytelling, and popular culture. She has contributed chapters to several essay collections, which range in topic from fan studies, to Doctor Who, to ecocriticism in the works of JRR Tolkien.

\section{TEXT}

Vol 22 No 2 October 2018

http://www.textjournal.com.au

General Editor: Nigel Krauth. Editors: Julienne van Loon \& Ross

Watkins

text@textjournal.com.au 